\title{
Effect of Inflatable Plastic Splints on Blood Flow
}

\author{
HEATHER ASHTON,** D.M., M.R.C.P.
}

Brit. med. F., 1966, 2, 1427-1430

Inflatable plastic splints have been in use for some time in the United States for the emergency splinting of fractures; they are also gaining popularity in casualty departments and fracture clinics in the United Kingdom. Splints of this type consist essentially of a double-walled transparent plastic jacket with a slide fastener and a screw valve in the outer wall for inflation (Fig. 1). The jacket is placed on the limb and inflated so as to support and immobilize the limb with a cushion of air under pressure. The air pressure recommended by the manufacturers (Jobst Institute, Inc.) for use in fractures is $30-40 \mathrm{~mm}$. Hg, the latter pressure being designated the "maximum safe pressure." A pressure of $30-40 \mathrm{~mm}$. $\mathrm{Hg}$ can be achieved by inflating such splints by mouth (Kelly and Fox, 1963) ; alternatively, the splints can be inflated with a hand bulb or a pressurized gas-container.

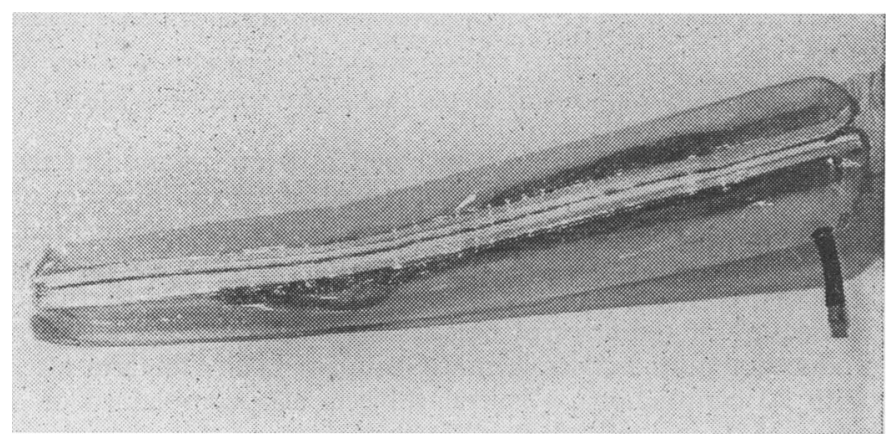

I.IG. 1.-Commercial splint (Jobst Inc.).

The advantages of inflatable plastic splints include ease of application, prevention of oedema, sterility, and transparency, so that wounds can be observed and radiography performed without removal of the splint. No disadvantages have so far been reported, apart from perspiration in the splinted limb, a problem easily overcome by applying an inner jacket of an absorbent material. However, with any device involving the application of an external pressure to tissues, the possibility arises that this pressure might interfere with the underlying circulation. Preliminary experiments (Pask, 1965; Walder, 1965) indicated that this might be the case, and a study was therefore undertaken to investigate the effects of inflatable splints on the blood flow in the tissues under pressure.

\section{Theoretical Considerations}

Ary factor which tends to increase tissue pressure, such as the application of an external pressure to a limb, will also reduce the transmural arterial pressure (blood pressure minus surrounding tissue pressure) and is thus likely to reduce the blood flow (Burton and Yamada, 1951). Many workers have shown that in human limbs and digits the application of an external pressure (with either air or water) does in fact decrease blood flow (Burton and Yamada, 1951 ; Yamada, 1954 ; Roddie and Shepherd, 1957 ; Gaskell and Krisman, 1958 ; Coles and Gough, 1960 ; Ashton, 1962a, 1962b ; Jennings, 1964).

These workers have also shown that if the external pressure is increased to a critical level sudden complete cessation of

* Lecturer in Clinical Pharmacology, University of Newcastle upon Tyne. E blood flow in the limb may result, even at transmural pressures well above zero. This phenomenon has been ascribed to critical closure of blood vessels (Burton, 1951). The transmural pressure at which complete cessation of blood flow occurs (flow-cessation pressure) depends on the degree of vasomotor tone. In normal subjects the flow-cessation pressure in the forearm at a plethysmograph water temperature of $34^{\circ} \mathrm{C}$. was found to vary over the range $10-68 \mathrm{~mm}$. $\mathrm{Hg}$ (mean $33.4 \mathrm{~mm}$. Hg) (Ashton, 1962a). The flow-cessation pressure may be considerably raised if the limb is cold, and it is significantly higher in certain pathological conditions such as hypertension (Ashton, 1962b).

The question of the extent to which an applied external pressure is transmitted to the tissues has been investigated by Thomson and Doupe (1949). These authors made direct measurements of tissue pressure under cuffs inflated around the arm and found that, except for tissues lying less than $5 \mathrm{~cm}$. from the cuff edges, $100 \%$ of the cuff pressure (over $\mathrm{n}$ range of 20 to $200 \mathrm{~mm}$. $\mathrm{Hg}$ ) was transmitted to all depths of tissue down to bone level. Since splints may enclose the whole limb or a considerable portion of a limb, it is clear that a large proportion of the underlying tissues will receive the full splintinflation pressure.

Thus in a normal limb with a mean blood pressure of 95 $\mathrm{mm} . \mathrm{Hg}$ and a tissue pressure near zero, a splint inflated to $40 \mathrm{~mm}$. $\mathrm{Hg}$ would reduce the transmural arterial pressure in most of the underlying tissues to the region of $55 \mathrm{~mm}$. $\mathrm{Hg}$, a level within the range of flow-cessation pressures for normal subjects under comfortably warm conditions. If the subject were shocked or cold it is even more likely that the flowcessation pressure would be reached. Even if cessation of flow did not occur, the evidence on pressure/flow relationships In human limbs (Burton and Yamade, 1951; Ashton, 1962a) indicates that a considerable reduction in blood flow may be associated with a drop in transmural arterial pressure of 30$40 \mathrm{~mm}$. Hg.

For these reasons the application of an inflatable splint i) a limb would be expected to cause not only a reduction but in certain circumstances a complete cessation of blood flow.

\section{Methods}

A range of inflatable splints of various sizes suitable for use on the arm or leg were made out of plastic sheeting $(1 / 100 \mathrm{in}$. $(0.25 \mathrm{~mm}$. $)$ thick). These consisted of double-walled tapered cylinders with two outlets in the outer wall. One of these outlets was connected to a mercury manometer for measuring the splint inflation pressure, and the other was joined to 4 rubber hand bulb for inflation of the splint (Fig. 2). These splints were placed over a limb in which the blood flow was recorded before, during, and after inflation of the splint to various pressures.

Blood flow in the forearm and calf was measured with mercury-in-rubber strain gauges (Devices Ltd.), as described by Whitney (1953), with a Dynograph pen recorder (Beckman Inc.). Calibration of the strain gauges was carried out on the limb to take into account compressibility of the tissues (Greenfield, Whitney, and Mowbray, 1963). Skin temperature was also recorded and found to be constant under an inflated 
splint, which acts as an insulator, in spite of changes in blood flow.

In all experiments a strain gauge and venous occlusion cuff were placed on a limb beneath the splint, at least $5 \mathrm{~cm}$. from either edge of the splint. The pressure in the venous occlusion

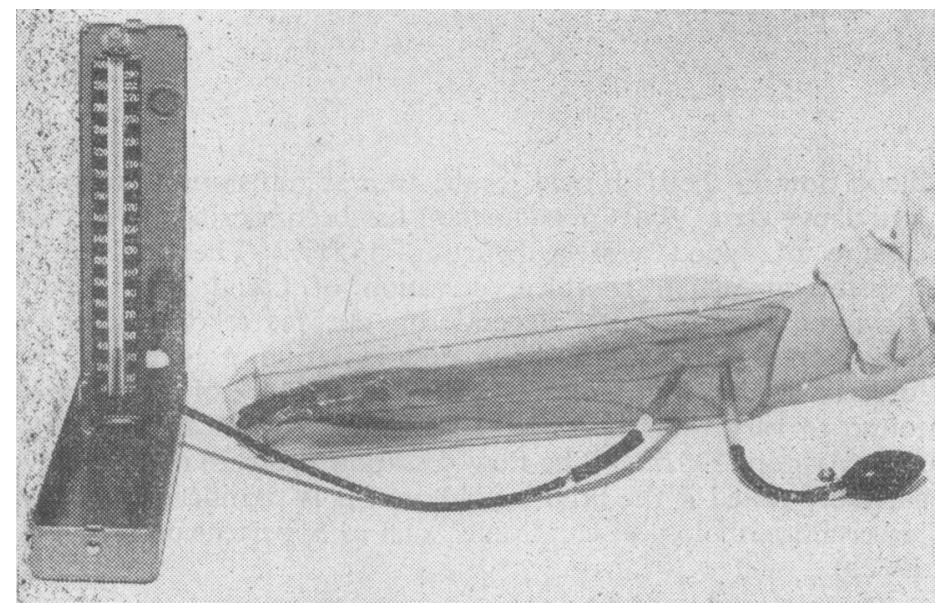

Fig. 2.-Experimental splint, showing hand bulb and manometer.

cuff was always at least $5 \mathrm{~mm}$. $\mathrm{Hg}$ greater than the splint inflation pressure and at least $5 \mathrm{~mm}$. Hg lower than the diastolic blood pressure, measured by auscultation. The adequacy of these pressure differences in measuring blood flow with pressure plethysmography has been demonstrated by Burton and Yamade (1951) and Ashton (1960). Usually the whole of the limb distal to the strain gauge was encased in the splint, but in a few experiments a shorter splint was used so that a second strain gauge and occlusion cuff could be used to measure blood flow simultaneously in a portion of the limb distal to the splint. In this way any artifact due to pressure of the splint on the strain gauge would be revealed, since the blood flow in the portion of the limb distal to a splint should reflect changes in blood flow in the more proximal portion under the splint.

The effect of inflation of a splint on the blood flow in the forearm or calf was measured in 15 subjects. These subjects included 10 males and 5 females between the ages of 19 and 52. Seven of the subjects were healthy medical students or colleagues, and five were hospital patients with normal cardiovascular systems who were under investigation or treatment of unrelated illnesses. Three patients had definitely abnormal cardiovascular systems. One male had been known to be hypertensive for eight months; he had been treated unsuccessfully with several antihypertensive drugs but was receiving no drugs at the time of investigation, when his blood-pressure was 190/ 120. One male had been treated for malignant hypertension and uraemia with intravenous methyldopa and peritoneal dialysis, but was not taking any drugs at the time of investigation, when his blood pressure was $180 / 120$. One woman was 37 weeks pregnant and had a hyperdynamic circulation with clubbing of the fingers and toes and hypertrophic osteoarthropathy of unknown cause; her blood pressure was 90/60.

All measurements of blood flow were made with the subject lying comfortably on a bed in a warm room (temperature $20-22^{\circ}$ C.). A resting period of at least 30 minutes was allowed before the blood flow was recorded. The limb in the splint was placed level with the sternal angle for most measurements, but in some cases the limb was raised to measured heights above this level in order to investigate the effect of lowering the local blood pressure hydrostatically.

\section{Results}

Inflation of the splint to $40 \mathrm{~mm}$. $\mathrm{Hg}$ produced a marked reduction in blood flow in the limb of all subjects. In six subjects the blood flow was apparently reduced to zero; in seven it was reduced to between 0.2 and $0.9 \mathrm{ml} . / 100 \mathrm{ml}$. tissue/min. In the remaining two (one a patient with hypertension) the blood flow was reduced approximately $30 \%$ and $z$ $50 \%$ respectively below the resting level. Inflation of the $\stackrel{\mathbb{Q}}{\unrhd}$ splint to $30 \mathrm{~mm}$. Hg also decreased the blood flow, but to a $\leftarrow$ less degree. Details of the subjects investigated and the values $\vec{F}$ for blood flow in the limb before and during splint inflation are shown in the Table.

Blood Flow in Limbs at Various Splint-inflation Pressures in 15 Subjects

\begin{tabular}{|c|c|c|c|c|c|c|c|c|}
\hline \multirow{3}{*}{ Subject } & \multirow{3}{*}{\multicolumn{2}{|c|}{$\begin{array}{l}\text { Sex } \\
\text { and } \\
\text { Age }\end{array}$}} & \multirow{3}{*}{ B.P.t } & \multirow{3}{*}{ Limb } & \multirow{2}{*}{\multicolumn{4}{|c|}{$\begin{array}{c}\text { Blood Flow (ml. } / 100 \mathrm{ml} . / \mathrm{min} .) \\
\text { at various splint pressures }\end{array}$}} \\
\hline & & & & & & & & \\
\hline & & & & & 0 & 30 & 40 & $\begin{array}{l}\text { 40-limb } \\
\text { raised } \neq\end{array}$ \\
\hline $\begin{array}{l}1 \\
2 \\
3 \\
4 \\
5 \\
6 \\
7 \\
8\end{array}$ & $\begin{array}{l}F \\
F \\
F \\
F \\
M \\
M \\
M \\
M\end{array}$ & $\begin{array}{l}20 \\
19 \\
20 \\
22 \\
38 \\
21 \\
21 \\
45\end{array}$ & $\begin{array}{l}100 / 65 \\
100 / 70 \\
130 / 85 \\
110 / 80 \\
110 / 80 \\
125 / 80 \\
125 / 80 \\
100 / 60\end{array}$ & $\begin{array}{c}\text { Forearm } \\
\text { " } \\
", \\
", \\
",\end{array}$ & $\begin{array}{l}5.3 \\
1.4 \\
4.0 \\
1.4 \\
1.5 \\
2.0 \\
4 \cdot 1 \\
3 \cdot 6\end{array}$ & $\begin{array}{l}3.3 \\
0.1 \\
\\
0.7 \\
0.7 \\
1.3\end{array}$ & $\begin{array}{l}0 \\
0 \\
0 \\
0 \\
0.5 \\
0.5 \\
0.6 \\
0.9\end{array}$ & $\begin{array}{l}0 \\
0\end{array}$ \\
\hline $\begin{array}{l}9 \\
10 \\
11 \\
12 \\
13^{*} \\
14^{*} \\
15^{*}\end{array}$ & $\begin{array}{l}M \\
M \\
M \\
M \\
F \\
M \\
M\end{array}$ & $\begin{array}{l}52 \\
40 \\
38 \\
19 \\
26 \\
25 \\
51\end{array}$ & $\begin{array}{c}110 / 80 \\
135 / 85 \\
110 / 80 \\
110 / 65 \\
90 / 60 \\
180 / 120 \\
190 / 120\end{array}$ & $\begin{array}{l}\text { Forearm } \\
\quad \text { ", } \\
\text { Calf } \\
\text { Forearm } \\
\text { Calf } \\
\text { Forearm }\end{array}$ & $\begin{array}{c}1.6 \\
7.5 \\
4.2 \\
1.9 \\
14 \\
2.5 \\
2.5\end{array}$ & $\begin{array}{l}0.4 \\
2 \cdot 0\end{array}$ & $\begin{array}{l}0 \\
0 \cdot 6 \\
2.0 \\
0 \cdot 2 \\
0 \\
1.8 \\
0.6\end{array}$ & $\begin{array}{l}0 \\
0 \\
0 \\
0 \cdot 6 \\
0\end{array}$ \\
\hline
\end{tabular}

* Abnormal subjects: two men with hypertension, one woman 37 weeks pregnant ith clubbing and hypertrophic osteoarthropathy.

B.P. refers

₹ Limb raised 9-35 cm. above sternal angle while splint inflated to $40 \mathrm{~mm}$. $\mathrm{Hg}$.

That the apparent decrease in blood flow on inflation of the $\overrightarrow{\mathscr{\theta}}$ splint was not due to some artifact caused by the pressure of the splint on the strain gauge is suggested by the findings that nearly all subjects showed a pronounced reactive hyperaemia on release of the splint, and that in all subjects tested rhythmic contraction of the forearm muscles after inflation of the splint produced typical ischaemic muscular pain in the forearm after $\stackrel{D}{\unrhd}$ 10 to 20 contractions. Several subjects also complained of a $\overrightarrow{\vec{P}}$ feeling of "pins-and-needles" in the fingers or toes after about $\frac{0}{3}$ 15 to 30 minutes of splint inflation. In addition, in three subjects the blood flow was measured simultaneously both under a splint inflated around the arm and upper forearm and also distally in the portion of the forearm not enclosed by the splint. In all cases the changes in blood flow in the distal part of the forearm closely followed those of the proximal part. A typical result is shown in Fig. 3.

In eight experiments the effect of raising the limb above heart level, thus reducing the blood pressure in the limb by the hydro- $\mathrm{O}$ static factor, was investigated. This procedure was considered relevant both in order to assess the effect of a lowered blood- O pressure on the blood flow under the splint and also because $\frac{T}{0}$

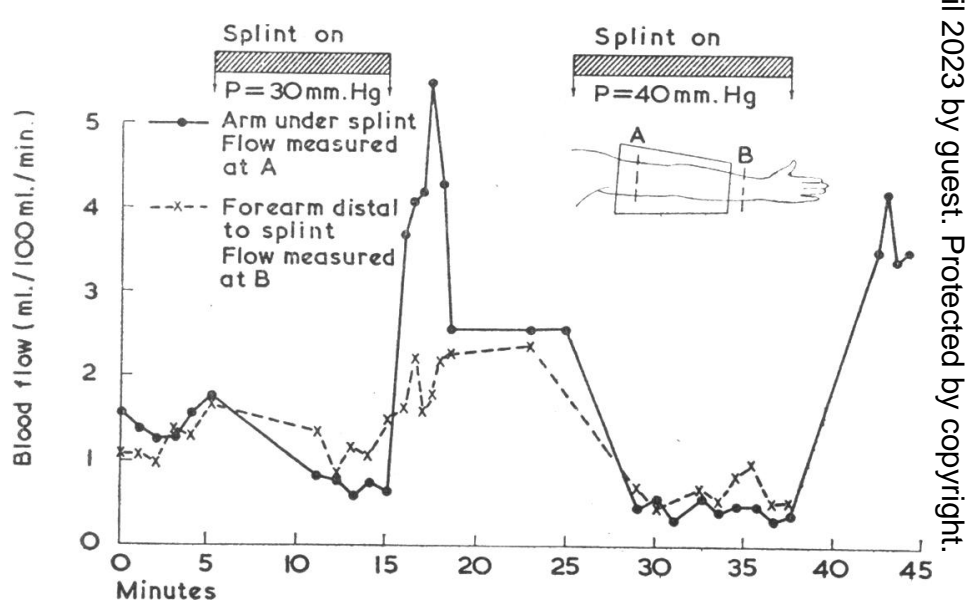

FIG. 3.-Blood flow in arm and forearm: effect of inflating splint on blood flow beneath splint and distal to splint. 
it is a common orthopaedic practice to raise a splinted limb after a fracture in order to reduce the development of oedema. The effect on the blood flow of raising the forearm in a normal subject without a splint is shown in Fig. 4. These findings agree with those of Holling and Verel (1957), who studied plethysmographically the circulation in the elevated forearm. When a splint was inflated the effect of raising a limb in all subjects was to reduce the blood flow still further. Cessation of blood flow could be precipitated by this means in all subjects except one, who was hypertensive. A typical effect is shown in Fig. 5. The results for all subjects are shown in the Table.

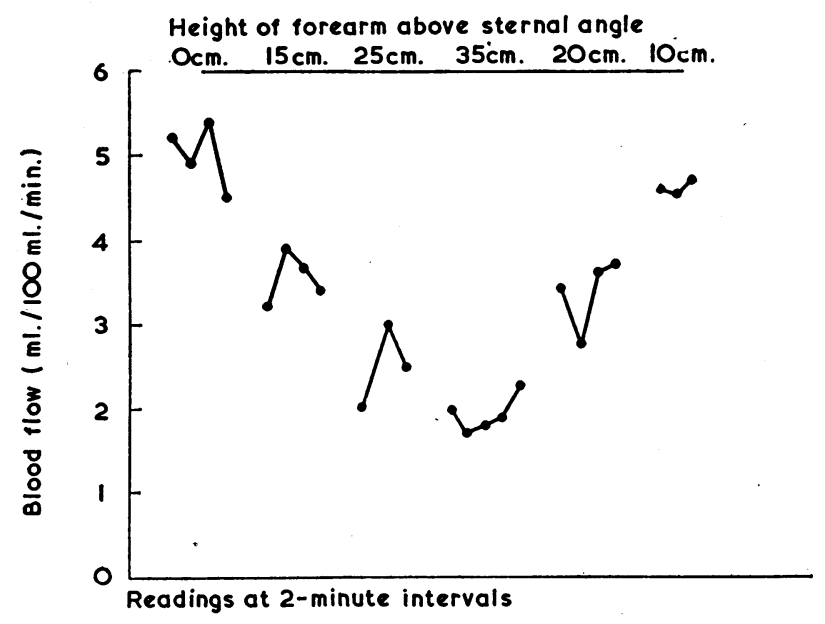

FIG. 4.-Blood flow in forearm: effect of raising forearm above level of sternal angle.

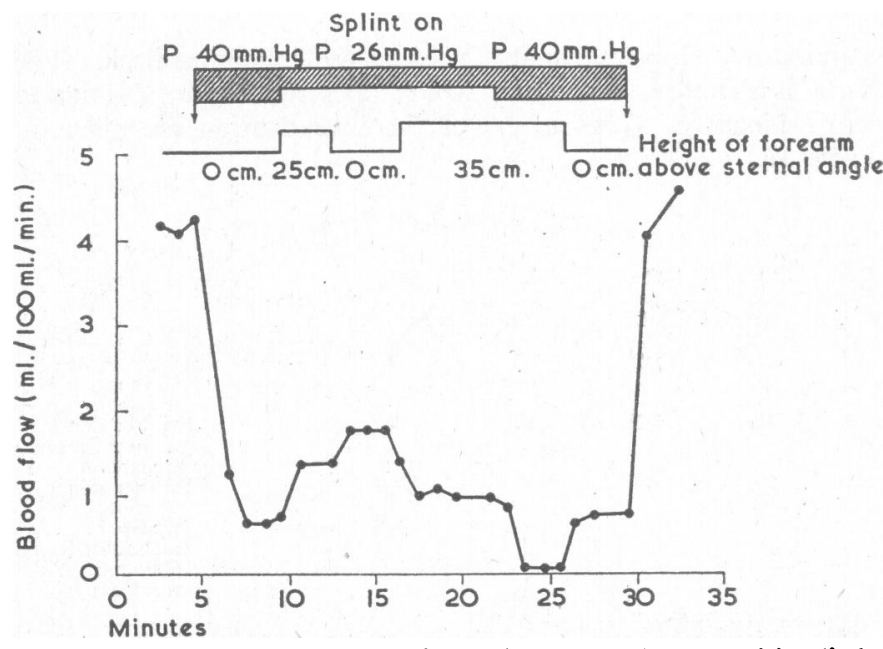

FIG. 5.-Blood flow in forearm: effect of inflating splint and raising limb.

In all cases the reduction in blood flow after inflation of the splint occurred promptly, usually within one to two minutes, and the reduced or zero blood flow was then maintained with little alteration for as long as the splint was inflated. There was no evidence of any circulatory readjustment that allowed for a resumption or increase of blood flow under the conditions of raised tissue pressure. Splints were kept inflated for periods varying from 10 to 45 minutes. Apart from sensations of tingling or "pins-and-needles" during inflation and reactive hyperaemia on deflation of the splint, there appeared to be no harmful effects from the reduction of blood flow to negligible levels for periods of up to 45 minutes in the subjects tested, all of whom had adequate "resting" blood flows.

\section{Discussion}

These results indicate that inflation of a splint around a limb to a pressure of $40 \mathrm{~mm}$. Hg greatly reduces the blood flow in the limb, often resulting in a negligible or even zero blood flow. These findings are explicable on theoretical grounds and appear to be at variance with the manufacturer's claim that $40 \mathrm{~mm}$. $\mathrm{Hg}$ is a safe pressure for inflation of a splint. It is unlikely that the results can be explained by an error or artifact in the method used ; they are supported by the observation of a reactive hyperaemia when the splint pressure is released and by the occurrence of ischaemic pain on muscular contraction during the period of splint inflation. In addition, Walder (1965), using the clearance rate of radioactive sodium as a measure of blood flow, obtained similar results.

The blood flow in a splinted limb may be further reduced by raising the limb above heart level, thus causing a local fall in blood pressure. This procedure may precipitate complete cessation of blood flow in splinted limbs in which a measurable blood flow persists when the limb is at heart level. It is likely that increased vasomotor tone due to haemorrhage or cold would also favour complete cessation of blood flow in splinted limbs, since these conditions are likely to raise the critical closing pressure of blood vessels (Burton and Yamada, 1951; Ashton, 1963).

The obvious implication of these findings is that the application of a splint inflated to $40 \mathrm{~mm}$. $\mathrm{Hg}$ might lead to ischaemic damage or even gangrene of tissues, particularly as such splints may need to be applied for considerable periods of time in patients who may be shocked or cold, who have already suffered tissue damage in the splinted limb, and who may in addition have unrelated vascular disease. However, it is noteworthy that no such damage has been reported, even after extensive use of this type of splint in the U.S.A. A possible explanation is that in practice such splints are not inflated to pressures as high as $40 \mathrm{~mm}$. Hg. The design of commercially available inflatable splints is such that there is no incorporated mechanism for measuring the splint-inflation pressure, and it is recommended that the splints should be inflated by mouth. It has been reported that subjects between the ages of 8 and 92 could inflate such splints by mouth to pressures between 30 and 40 $\mathrm{mm}$. Hg (Jobst Inc., personal communication). However, in the present investigation a trial among colleagues and medical students revealed that most subjects had great difficulty In inflating the splints used to pressures over $30 \mathrm{~mm}$. $\mathrm{Hg}$.

The present results show that a splint-inflation pressure of $30 \mathrm{~mm}$. $\mathrm{Hg}$ produces a smaller reduction in blood flow than a splint-inflation pressure of $40 \mathrm{~mm}$. $\mathrm{Hg}$, although in some cases the reduction was still considerable. It might therefore seem safer to recommend that splints of this type should not be inflated above $30 \mathrm{~mm}$. Hg. However, a splint inflated to $\mathbf{3 0}$ $\mathrm{mm}$. $\mathrm{Hg}$ gives considerably less support to a limb than one inflated to $40 \mathrm{~mm}$. $\mathrm{Hg}$, and the degree of immobility achieved is unlikely to be sufficient for all emergency uses. It is unlikely, for example, that it would give sufficient protection to a patient in a lifeboat in heavy seas.

To overcome these difficulties experiments are now in progress with a new design of inflatable splint in which longitudinal sections are inflatable but the two plastic layers are sealed together between the inflated sections. In this way pressure is applied to sections of the limb rather than to the whole limb. Preliminary studies with this design are encouraging and indicate that it is possible to get good limb support and immobilization without great reduction in blood llow. These studies will be reported in a later communication.

\section{Summary}

The effect of the application of inflatable plastic splints to the arm or leg on the circulation in the underlying limb was investigated in 15 subjects. The blood flow in the forearm or calf was measured with mercury-in-rubber strain gauges before, during, and after inflation of the splints to various pressures for durations of 10 to 45 minutes. 
Inflation of a splint to $40 \mathrm{~mm}$. $\mathrm{Hg}$ caused a marked reduction In blood flow in the limb in all subjects. Complete cessation of blood flow in the limb occurred in six subjects, and a reduction in blood flow to levels between 0.2 and $0.9 \mathrm{ml}$./ $100 \mathrm{ml}$. tissue $/ \mathrm{min}$. occurred in seven.

Inflation of a splint to $30 \mathrm{~mm}$. $\mathrm{Hg}$ caused a similar but less pronounced reduction in blood flow.

Raising the limb above heart level, combined with splintInflation, still further reduced the blood flow, resulting in complete cessation of the flow in five out of six subjects.

A theoretical explanation of these findings and some implications concerning the use of inflatable splints for the emergency treatment of fractures are discussed.

I am grateful to Mr. J. Sadler for valuable technical assistance, to Professor G. A. Smart for allowing access to patients under his care, and to Professor J. W. Thompson and the late Professor E. A. Pask for advice and assistance.
Requests for reprints should be addressed to Dr. H Ashton, Department of Pharmacology, The Medical School, University of Newcastle upon Tyne.

\section{REFERENCES}

Ashton, H. (1960). "Critical Closing Pressure in Man." D.M. Thesis, University of Oxford.

(1962a). Clin. Sci., 22, 79.

- (1962a). Clin. Sci., 22, 79.

二 (1962b). Ibid. med. Bull., 19, 149

Burton, A. C. (1951). Amer. F. Physiol., 164, 319.

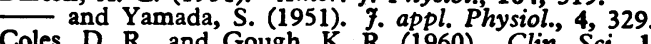

Coles, D. R., and Gough, K. R. (1960). Clin. Sci., 19, 587

Gaskell, P., and Krisman, A. M. (1958). Circulat. Res., 6, 461.

Greenfield, A. D. M., Whitney, R. J., and Mowbray, J. F. (1963). Brit. med. Bull., 19, 101.

Holling, H. E., and Verel, D. (1957). Clin. Sci., 16, 197.

Jennings, A. M. C. (1964). Brit. 7. Anaesth., 36, 683.

Kelly, A. P., and Fox, J. I. (1963). Arch. environm. Hlth, 7, 282

Pask, E. A.' (1965). Personal communication.

Roddie, I. C., and Shepherd, J. T. (1957). 尹. Physiol. (Lond.), 136, 498

Thomson, A. E., and Doupe, J. (1949). Canad. J. Res., 27, 72.

alder, D. M. (1965). Personal communication.

Whitney, R. J. (1953). F. Physiol. (Lond.), 121, 1

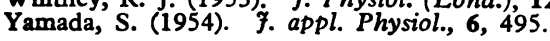

\title{
Renin Secretion by the Denervated Kidney
}

\author{
EDMUND J. LEWIS,* M.D.; M. DONALD BLAUFOX, $†$ M.D., PH.D. ; ROGER B. HICKLER; $\ddagger$ M.D.
}

Brit. med. F., 1966, 2, 1430-1431

The mechanisms regulating renin secretion by the kidney are conjectural at present. The demonstration of renin in the cells of the juxtaglomerular apparatus (Edelman and Hartroft, 1961) and the anatomical evidence that these cells are innervated (Barajas, 1964) have led some investigators to suggest that the sympathetic nervous system may play a part in controlling the renin-angiotensin-aldosterone system (Wathen et al., 1965; Gordon et al., 1966).

In man the change of posture from the recumbent to the upright position is associated with an elevation of the peripheral venous renin activity (Conn et al., 1965). This suggests increased renin secretion by the kidney.

We have studied three renal homograft recipients in order to observe the effect of renal denervation upon the postural renin response.

\section{Methods}

Case Material.-Two subjects who had previously donated a kidney served as normal controls. Three renal transplant recipients made up the experimental group (see Table I).

Procedure.-All of the patients were on an ad lib. salt intake before the study. Blood samples were drawn after each subject had been erect and active for four hours and again after four hours of recumbency. Peripheral venous renin activity was determined by Hickler's modification (Blaufox et al., 1966) of the method of Boucher et al. (1964). This modification differs from the originally described method in so far as (1) after incubation the resin-containing peptide is washed and eluted by the batch method, no column being used, and (2) the elutions are collected in a cold flask and dried rapidly on a flash

- Research Fellow, Renal Laboratory, Peter Bent Brigham Hospital, Boston, Massachusetts. Present address: Kidney Disease Branch, Division of Chronic Diseases, U.S. Public Health Service, Washington, D.C.

t Research Fellow, Renal Laboratory, Peter Bent Brigham Hospital, Boston, Massachusetts. Present address: Albert Einstein College of Medicine, Bronx, New York.

¥ Assistant Professor, Harvard Medical School ; Director, Hypertension Laboratory, Peter Bent Brigham Hospital, Boston, Massachusetts. evaporator. No acetic acid is used in the collection flask. The result is therefore a product which does not need sublimation before bioassay. The results of the investigation are given in Table II.

\begin{tabular}{|c|c|c|c|c|c|c|}
\hline \multirow{2}{*}{$\begin{array}{l}\text { Case } \\
\text { No. }\end{array}$} & BUN & $\mathrm{Cr}_{3}$ & $\mathrm{C}_{\mathrm{cr}}$ & $\mathrm{U}_{\mathrm{Na}}$ & \multirow{2}{*}{ Urinalysis } & \multirow{2}{*}{ Remarks } \\
\hline & \multicolumn{2}{|c|}{ (mg./100 ml.) } & $(\mathrm{ml} . / \mathrm{min})$. & $\mathrm{mEq} / 24 \mathrm{hr}$ & & \\
\hline 1 & 17 & 1.9 & 67 & 270 & Negative & $\begin{array}{l}\text { Identical twins; } \\
10 \text { months post }\end{array}$ \\
\hline 2 & 18 & $1 \cdot 2$ & 60 & 150 & . & $\begin{array}{l}\text { transplant } \\
\text { Brother donor; } \\
2 \text { months post- }\end{array}$ \\
\hline 3 & 23 & 1.5 & 93 & 200 & & $\begin{array}{l}\text { transplant } \\
\text { Brother donor; } \\
11 \text { months post- } \\
\text { transplant; } \\
\text { maintained on } \\
500 \text { mg. Aldo- } \\
\text { met* daily }\end{array}$ \\
\hline
\end{tabular}

BUN $=$ Blood urea nitrogen. $\mathbf{C r}_{8}=$ Serum creatinine. $\mathrm{C}_{\mathrm{wr}}=$ Creatinine clearance. $\mathrm{U}_{\mathrm{Na}}=$ Sodium output for the 24 hours preceding the study.

- Aldomet (methyldopa).

TABLB II.-Results. Peripheral Venous Renin Activity Levels are Recorded as Nanograms Angiotensin II Evolved per $100 \mathrm{ml}$. Plasma per 3-hour Incubation

\begin{tabular}{|c|c|c|c|c|}
\hline & \multicolumn{2}{|c|}{ Supine } & \multicolumn{2}{|c|}{ Erect } \\
\hline & $\begin{array}{c}\text { B.P. } \\
\text { (mm. Hg) }\end{array}$ & $\begin{array}{c}\text { Renin } \\
\text { (ng. A/100 ml.) }\end{array}$ & $\begin{array}{l}\text { B.P. } \\
(\mathbf{m m} . \mathbf{H g})\end{array}$ & $\begin{array}{l}\text { Renin } \\
\text { (ng. } \mathrm{A} / 100 \mathrm{ml} \text {.) }\end{array}$ \\
\hline Controls $\left\{\begin{array}{l}\mathrm{A} \\
\mathrm{B}\end{array}\right.$ & $\begin{array}{l}134 / 88 \\
130 / 82\end{array}$ & $\begin{array}{l}123 \\
127\end{array}$ & $\begin{array}{l}118 / 80 \\
105 / 75\end{array}$ & $\begin{array}{l}292 \\
426\end{array}$ \\
\hline Patients $\left\{\begin{array}{l}1 \\
2 \\
3\end{array}\right.$ & $\begin{array}{l}132 / 80 \\
130 / 85 \\
164 / 110\end{array}$ & $\begin{array}{r}36 \\
342 \\
414\end{array}$ & $\begin{array}{l}124 / 92 \\
136 / 90 \\
130 / 105\end{array}$ & $\begin{array}{r}317 \\
677 \\
2,030\end{array}$ \\
\hline
\end{tabular}

Ten recovery experiments with Hypertensin-Ciba (angiotensin amide) resulted in recovery of $76-100 \%$ of the known. Mean recovery in these experiments was $90 \% \pm 7 \%$ (S.D.). Fifty duplicate samples resulted in a mean difference of $10.4 \%$ in reproducibility of the renin activity measured in peripheral venous blood. 